\title{
Recurrent Central Nervous System Lymphoma
}

National Cancer Institute

\section{Source}

National Cancer Institute. Recurrent Central Nervous System Lymphoma. NCI

Thesaurus. Code C138019.

The reemergence of central nervous system lymphoma after a period of remission. 